\title{
QUANDO AS CRIANÇAS FALAM DE SUA ESCOLA E (NOS) ENSINAM...
}

\author{
MARTINE LANI-BAYLE \\ https://orcid.org/0000-0002-4549-8872 \\ Universidade de Nantes
}

RESUMO O trabalho que realizamos ao longo da nossa carreira, com extensões no Brasil em particular, mostra - se necessário for - o que as crianças são capazes de fazer e o que elas esperam de suas próprias capacidades narrativas, fazendo ecoar em nós, o que podemos esperar delas em educação, na formação e na pesquisa, vinculando saberes vividos e saberes acadêmicos. Mas, se a narração, apesar disso, ainda permanece desvalorizada no mundo das reflexões, ela é, no entanto, a verdadeira "característica humana" (VICTORRI, 2002), aquilo que nos constitui como humanos no sentido mais profundo do termo: sem ela, nossa reflexividade não avançaria, nossa aprendizagem não aconteceria ou mal se faria. Então por que não levar em conta a narrativa e cultivá-la desde tenra idade especialmente na escola? E se contássemos uma história, a nossa história com os outros e entre os outros, em busca e à escuta desta capacidade narrativo-reflexiva primeva que nos acompanha em todas as idades da vida?

Palavras-chave: Narração. Capacidade narrativo-reflexiva. Narrativas de crianças. Escola.

\section{ABSTRACT WHEN CHILDREN TALK ABOUT THEIR SCHOOL AND TEACH (US)...}

The work we have done throughout our career, with extensions in Brazil in particular, shows - if necessary - what children are capable of doing and what they expect from their own narrative skills, echoing in us what we can expect from them in education, training and research, linking lived knowledge and academic knowledge. However, if narration continues to be undervalued in the world of reflection, it is the true "human characteristic" (VICTORRI, 2002) that constitutes us as humans in the deepest sense of the term: without it, our reflectivity would not advance, our learning would not take place or would

1 Título de uma conferência publicada nos anais do 35e Congrès de la Fédération Nationale des Associations des Rééducateurs de l'Éducation Nationale (FNAREN), Blois, França, 28 de maio de 2020. 
be poorly done. So, why not take into account narration and cultivate it from an early age, especially in school? And what if we told a story, our story with others and among others, in search of and listening to this primitive capacity for narration-reflection that accompanies us in all ages of life?

Keywords: Narration. Narrative-reflective capacity. Children's stories. The school.

\section{RESUMEN CUANDO LOS NIÑOS HABLAN DE SU ESCUELA Y (NOS) ENSEÑAN...}

El trabajo que hemos realizado a lo largo de nuestra carrera, con extensiones en Brasil en particular, muestra - si es necesario - lo que los niños son capaces de hacer y lo que esperan de sus propias habilidades narrativas, haciendo eco en nosotros de lo que podemos esperar de ellos en la educación, la formación y la investigación, vinculando el conocimiento vivido y el conocimiento académico. Sin embargo, si la narración sigue estando infravalorada en el mundo de la reflexión, ella es la verdadera "característica humana" (VICTORRI, 2002), la que nos constituye como humanos en el sentido más profundo del término: sin ella, nuestra reflexividad no avanzaría, nuestro aprendizaje no se produciría o estaría mal hecho. Entonces, ¿por qué no tener en cuenta la narración y cultivarla desde una edad temprana, especialmente en la escuela? ¿Y si contáramos una historia, nuestra historia con otros y entre otros, en busca y escuchando esta capacidad primitiva de narración-reflexión que nos acompaña en todas las edades de la vida?

Palabras clave: Narración. Capacidad narrativa-reflexiva. Narraciones infantiles. La escuela.

\section{Introdução}

Para conquistá-las [as palavras], é preciso pesá -las, observá-las, aprender suas histórias, e depois brincar com elas, sorrir com elas. Aproximarse delas para saboreá-las melhor, cumprimentá -las, e sempre um pouco à distância se dizer eu já a tenho na ponta da língua - o gosto da palavra que já não me falta mais. (DELERM, 2010, p. 7)

Para muitos, a capacidade narrativa é uma característica da infância, indigna da adultez, quando ela seria substituída pela capacidade argumentativa. Para outros, as crianças só se- riam capazes de contar uma história entre sete e nove anos de idade: a capacidade narrativa seria impossivel antes da célebre "idade da razão", ali pelos sete anos. Ou, ao contrário, seria justamente aos sete anos que ela seria bloqueada? Se assim fosse, a narrativa da experiência não poderia ser solicitada às crianças pequenas. E elas só podem ser vistas através do que os mais velhos dizem delas e pensam por elas - além do mais, sem elas. 
(Re)habilitar a narratividade e a

\section{sua importância no ensino e na pesquisa}

Dar voz sobretudo aos pais, às crianças e aos profissionais da primeira infância, escutando -os e fazendo ouvir suas vozes, uns aos outros: uma perspectiva de pesquisa e de prática a ser mais desenvolvida. (BROUGÈRE, 2007, p. 283, grifos do autor)

Por nossa vez, e confiando no que a prática nos mostrou, discordamos das cautelas já mencionadas quanto às possibilidades narrativas das crianças. E na movência do homo narrans do qual fala Victorri (op. cit.), nos inscrevemos na linha de Stern (apud GOLSE, 2008), para quem chegamos ao mundo envolvidos em camadas "pré-narrativas" das quais escapariamos, assim que surge a linguagem. Esboços de narrativas, que podem dar origem, desde muito cedo, a micronarrativas em que as crianças, ainda bem pequenas, expressam sua experiência cotidiana. E, assim fazendo, descobrem o mundo.

Surfando nessa possibilidade, fomos ouvir o que as crianças tinham a nos dizer e a nos ensinar sobre suas vidas, por exemplo, na escola desde o jardim da infância, considerando-as como testemunhas do que vivem ali e como vivem. Nesse sentido, torna-se impossível não considerar a legitimidade de suas palavras antes de lhes propor programas, lugares ou modalidades viáveis para elas e que produzam saberes ao seu alcance.

De fato:

- Ouvindo as crianças, elas nos mostram o caminho de suas necessidades e desejos.

- Negligenciando-as, passamos ao lado do que elas experimentam. A consequência dessa negligência é oferecerlhes um mundo inadequado e inapto para preencher objetivos educacionais e formativos.
Os desafios desse reconhecimento, como podemos ver, são altos. E "cale a boca!" é o que os professores mais dizem em sala de aula (pelo menos na França). De fato, isso é mais tranquilizador ou confortável para os adultos em seu desejo de supremacia na vida cotidiana, seja na família, na escola, nos órgãos de decisão e mesmo nas ciências que estudam a criança. E estas devem ainda contar suas histórias, pois essa capacidade se degrada se não nos servirmos dela, se fizermos pouco ou mal uso de sua função reflexiva. Assim, todo mundo sai perdendo pelo pouco reconhecimento, pelo pouco ou fraco estímulo.

Mas se é possivel narrar desde tenra idade e se a narração estiver vinculada ao desenvolvimento, como proceder para estimular e recolher as narrativas de crianças quando temos pouca experiência nessa área? Quais são os motores ou os "gatilhos narrativos"? (MEIRIEU, 1993, p. 126). Assim como acontece com o adulto, o procedimento que suscita a reflexividade narrativa sobre a experiência vivida se operacionalizaria na relação discursiva narrador/ narratário, o que se chama de "coconstrução", na qual os protagonistas (ouvinte e narrador - mesmo crianças) se engajam e se implicam. Não é, portanto, uma atividade solipsista, isolada, sem efeito formativo, pela falta do "outro" como respondente externo. Ora, essa narrativa que parte de uma curiosidade a ser esclarecida requer um acompanhamento dialógico, implícito, que raramente se realiza de forma simples ou espontânea, de si para si mesmo (embora se considere vieses autodialogantes não monologantes). Em todo caso, é necessária uma descentralização, um espaço "reflexionante", a partir da tomada de consciência das sensações e sentimentos (F2), associados às informações provenientes do vivido (F1), para permitir a existência de um espaço de reflexividade (F3) (LANI-BAYLE, 2006). ${ }^{2}$

2 É a Piaget (1947) que devemos a distinção das etapas 
A partir de então, a reflexão aparece como algo fundamental. Mas, para que isso ocorra, será suficiente dar voz às crianças, especialmente quando thes tem sido muitas vezes negada? Isso não é tão simples, ou imediato, nem a pedido nem sob ordem. Em todo caso, constatamos que o processo de questionamento requer modalidades particulares para que ele ocorra e se realize. Então, o adulto se engaja: e o que acontece quando falamos autenticamente com as crianças e as escutamos, respeitando-as? Destacamos que ouvi-las também é falar com elas, deixá-las falar umas com as outras, uma vez que a narrativa de uma desencadeia a da outra...

Essa capacidade narrativa é também social, pois se alimenta de interatividades. Ela é feita e só pode surgir, ser validamente exercida, em reciprocidade, em confiança, com respeito partilhado: em pé de igualdade de humano para humano. Portanto, e quaisquer que sejam as relações hierárquicas, de idade, por exemplo, que possa existir entre os protagonistas, alternadamente o narrador - quem é ouvido - e o narratário - quem escuta -, mostram uma dificuldade prática. Ainda maior quando existe uma diferença geracional entre eles, muitas vezes percebida como uma relação de autoridade ou de precedência. Não seria um dos principais impasses na aplicação do processo junto à criança quando se é adulto. Por que jogar essa dificuldade sobre ela, sobre uma incapacidade da sua parte, por ser demasiada jovens para fazer de sua experiência uma narrativa?

\section{Primeiros passos na pesquisa: dizer para aprender?}

E como não nos perguntar doravante se é uma

da narrativa em termos de "reflexionamento" (correspondendo ao que denominei F2), depois de "reflexão" produtora de saberes (que denominei F3). Sendo o nivel F1 a base factual que requer o uso de palavras para se tornar pensável (F3). alegria ou uma desgraça para cada criança aprender? Esta pergunta deve ser sempre feita antes de forçá-la a sentar, ouvir, repetir. Ela poderá nunca mais ser inocente. (BENAMEUR, 2000, p. 27)

\section{Da criança e sua história}

Estamos divididos entre a avidez de conhecer e o desespero de ter conhecido. (CHAR, 1948, p. 3)

Como cheguei a construir tais reflexões? 0 que me alertou para a importância da capacidade narrativa no que diz respeito ao desenvolvimento cognitivo foi minha experiência profissional como psicóloga clínica de crianças, em situação de vulnerabilidade, a maioria colocada em famílias de acolhimento. À época (comecei a trabalhar com elas em 1974), as que eram recebidas ainda muito jovens frequentemente não eram informadas sobre a história anterior ao acolhimento (o que denominei "proibidas de saber"3) ou então eram desinformadas (o que chamei de scordatura) (Lani -Bayle, 2006), acreditava-se que era para que não sofressem por um saber considerado dificil (pois se tratava delas). Como se o trauma viesse, não do que tinham vivido, mas do simples fato de saber o que lhes tinha acontecido: é este último saber que se projetava então como perigo em suas vidas.

Ora, havia notado que essas crianças também se encontravam frequentemente em sérias dificuldades na escola (tema que trabalhei de forma longitudinal na minha primeira tese, em 1979, publicada em 1983). Fiz então a ligação entre desinformação e fracasso escolar, postulando que todo saber se tornava de fato perigoso para elas, quando percebiam que

3 Mais tarde, encontrei um trabalho adicional em Boimare (1999) que tratava, na origem do processo, com os "medos de aprender", que o autor percebeu em algumas crianças. E ele cativa essas crianças através de contos e narrativas míticas, que contam histórias muito mais terriveis do que as delas e, portanto, presentes nos livros da escola. O suficiente para descongelar a sua relação com o saber. 
Ihes escondiam alguma coisa para protegê-las: e se o que a escola ensinava também pudesse colocá-las em perigo? Mais vale fechar-se, por lealdade, para aqueles que educam e em quem você confia.

Mais tarde, refinei essa hipótese, percebendo que a máscara ou a desarmonia imposta entre suas vidas e o que thes teria sido contado (scordatura), ou não, as tornava incapazes de narrar suas vidas e, portanto, de usar a função narrativa que nos constitui como humanos e que nasce na história das nossas origens, dos nossos começos. Assim, não era apenas o acesso aos saberes fundadores que thes fora negado, mas o próprio uso da narração que nos historiciza e nos faz entrar no mundo dos Homens, Ricœur (1990, 167-198) chama de “identidade narrativa".

\section{Rumo ao "dizer para aprender"}

Ouvindo as crianças, percebemos que a educação não é apenas uma relação com os saberes, com o legado do passado, é também uma relação com o que está acontecendo no dia-a-dia e uma relação com o futuro. É através desta tripla realidade que elas dão sentido à sua educação e constroem sua identidade. (MONTANDON, 1997, p. 228)

Quando deixei a função de psicóloga clínica e ingressei na universidade, nos anos 1990, em Ciências da Educação, dei início a uma primeira pesquisa com populações mais extensas e até mesmo vindas de diversos horizontes, para (in)validar essas hipóteses. E se o desenvolvimento da relação com o saber estivesse ligado ao possivel exercício da função narrativa? Reciprocamente, podemos perguntar se não poderíamos contribuir para a emergência de saberes nos alunos pelo viés da indução a uma reflexividade narrativa, solicitada ou acompanhada pelo professor, num quadro social obviamente não intrusivo, nem íntimo, mas social, tranquilizador, que estimulasse e acalmasse ao mesmo tempo.

A fim de avaliar essas pistas intuitivas, iniciei uma primeira pesquisa na Universidade de Nantes, ${ }^{4}$ que se apoiou na constatação empírica de que a dimensão narrativa da linguagem oral é insuficientemente considerada nas escolas, em comparação com as outras dimensões (particularmente explicativa, argumentativa, descritiva e informativa).

A principal hipótese subjacente a esse trabalho era a de que a capacidade narrativa, pouco reconhecida pela escola que favorece mais o argumentativo, estaria fortemente relacionada com as diversas formas de sucesso escolar. E, entre os contornos que essas formas podem assumir, é a narrativa em primeira pessoa que teria uma função chave nesse processo: a escolarização teria lugar onde a narrativa é possível. Assim, a uso explícito de uma abordagem narrativa no campo pedagógico e no acompanhamento das práticas escolares, em diferentes disciplinas, repercutiria sobre outros tipos de linguagem solicitados pela escola, articulando-se com eles e com as aprendizagens. Isso contribuiria para melhorar o conhecimento da língua e o sucesso escolar, particularmente pelo viés da ajuda à reintegração da pessoa em seu percurso de vida e em seu desenvolvimento concomitante, e até mesmo na emergência da autoconfiança e da autoestima.

De modo geral, as atitudes observadas na pesquisa evidenciaram relações extremas com a expressão narrativa nas salas de aula, variando do quase nada à invasão, dependendo dos níveis e dos contextos. E quando se tratava das aulas reunindo crianças com um currículo escolar perturbado, a fala dos alunos aparecia mais claramente, seja com numerosas onomatopeias ou palavras inapropriadas, seja de forma desordenada, não temporal, mal controla-

4 Cf. pesquisas realizadas nos anos finais do ensino fundamental I (Lani-Bayle, 1999, p. 196-203). 
da e irrelevante. No entanto, é aí que as relações no seu todo são as mais personalizadas, porém sem distância. Foi possível perceber ainda que deixá-las tomar a palavra perturba ou assusta rapidamente o professor que não sabe o que fazer nessa situação. Quando isso ocorre, a tendência é tentar contê-las em vez de contribuir para o seu desenvolvimento e exploração - um clima que geralmente é mais pacífico nas salas de aula comuns.

0 que guardamos dos resultados da pesquisa remete principalmente à mudança de atitude dos professores - particularmente no que concerne à circulação da fala - com relação aos alunos em geral e, particularmente, com aqueles em dificuldade escolar. Sentindose confiantes face a essa mudança de atitude, mesmo que leve tempo, os alunos passam a se expressar, sabendo que serão ouvidos. Esse desabrochar relacional no ambiente escolar se fez notar nos bons resultados na escolaridade, que poderia, em caso de fracasso, serem desviados para outros resultados além da marginalidade, como se constata frequentemente, seja pelo isolamento, seja pela agressividade. É de fato notável o quanto a agressividade pode ocupar o lugar vazio deixado pela fala e vice-versa, como bem estudou Dolto (1987), por exemplo. E o trabalho, ao enfatizar o impulso e o acolhimento do narrativo, impactou sobre os resultados escolares e as aprendizagens dos alunos, sem que nada de diferente ou de extraordinário tivesse sido feito a esse respeito. Apenas passou pelo viés narrativo.

Essa mudança dos hábitos escolares gerou um relaxamento da tensão, momentos privilegiados de proximidade pela autenticidade acrescida, feita de respeito mútuo e de reconhecimento do outro, passando do eu de um para o eu do outro e vice-versa: essa prática reforçada contribuiu de fato para que os alunos e também seu professor interagissem de outra forma, o que criou entre eles uma re- lação que chamei de "clínico-dialógica" (Lani -Bayle, 2019). Para além de suas contribuições específicas, a pesquisa evidenciou o seguinte questionamento: podemos aprender sem narrar oralmente ou por escrito? Traduzir em palavras uma experiência dá forma ao pensamento, transforma o sujeito que se forma como autor de suas aprendizagens.

No final da pesquisa, foram consideradas fundamentais três fases distintas do dispositivo de animação pedagógica: 1. sensibilizar os professores para os efeitos da narração; 2 . enfatizar, desde cedo, as práticas da narração nos momentos de formação; 3. acompanhar o desenrolar das situações e reflexões e criar um trabalho de equipe sobre o que a narração propicia a todos, incluindo os adultos.

Depois de estudar os testemunhos das crianças sobre sua experiência escolar, voltamos a ver o que as crianças em dificuldade poderiam dizer sobre sua relação com o saber.

\section{Compreender o fracasso através da narração}

É apenas com um objeto em desordem que as histórias começam. (HANDKE, 1971, p. 34)

Chatellier (2000) realizou para sua tese um trabalho de pesquisa com objetivos e perspectivas semelhantes, junto a alunos com histórico de fracasso escolar. 0 que eles contam sobre a experiência vivida na escola não se inventa e permite melhor compreendê-los. Aqui estão alguns exemplos:

Expressão de ansiedade diante de uma situação desconhecida:

Eu sei muito bem como é a leitura: porque com a Sra. Y, você sabe, bom, a gente costumava fazer coisas assim, escondendo palavras, escondendo escritas, e depois precisava lembrar. A leitura é a mesma coisa, mas há algo dificil

5 Os excertos foram retirados da tese de Chatellier, 2000. 
porque tem muitas palavras. Então, primeiro eu me lembro e depois, de repente, tenho medo na minha cabeça.

Eu acho que sei ler, quero dizer, consigo reconhecer as palavras. Eu não concordo com a professora quando ela diz que eu não sei ler nada. Mas é engraçado, porque se eu quiser entender uma história, eu não preciso ler todas as linhas, senão fica tudo confuso: só a minha voz na minha cabeça fica falando e eu não entendo nada. Então, eu procuro palavras-chave, eu acho que entendi alguma coisa e depois eu tenho medo, então começo a ler tudo de novo do começo ao fim. E eu não entendo nada. E a professora me faz perguntas, é claro.

Intrusão do contexto conhecido, o familiar - dificil passar de um ambiente a outro:

Tá vendo, lá estão as plaquinhas: então eu olho pra elas e quando eu reconheço duas ou três ou quatro, nem todas, tá? Tudo bem, eu sei que vou conseguir. Porque duas, por exemplo, eu olho para qual vai antes da outra e coloco em ordem e depois tento compreender as outras e eu encontro, mas de repente vem mamãe [...] ui, não [...] quero dizer, a professora que diz: 'acabou'.

Para mim, uma leitura silenciosa é fácil e dificil, as duas coisas. É divertido ao mesmo tempo, viu? Por exemplo, é fácil, porque assim que começa eu não tenho que ler on-line. E é difícil, porque quando acho que compreendi, eu ouço a voz da minha mãe dizer: 'Leia tudo'. E, no entanto, a minha mãe não está aqui!

Como se pode constatar, quando ouvimos as crianças, os saberes se transformam e a compreensão acontece. É preciso reconhecer que é bem diferente do que se lê sobre a reflexividade das crianças nos relatórios escolares, em termos habituais: "deficiências"; "pode fazer melhor"; "incapaz de acompanhar"; "não se esforça"; "não presta atenção" [...] chegando mesmo a comentários humilhantes, às vezes públicos: "péssimo aluno"; "com os pais que ele tem [...]". Dessa forma, vemos como é pos- sível aproveitar os ensinamentos das narrativas da experiência vivida na sua relação com a formação, sem que para isso, se ponha na base um sentimento, de cunho privado a ele vinculado, e que não é o saber que deve ser explorado diretamente na escola. Se o saber existencial alimenta o saber escolar, cada um tem seu lugar e o respeito às fronteiras é fundamental.

\section{Uma exploração junto aos alunos: egressos e atuais}

Há uma presença notável do mito da escolaridade quando se fala de aprendizagem, que ignora a aprendizagem da vida, da experiência e da experiência de vida de cada pessoa. (VASCONCELOS, 2003, p. 268)

A fim de validar o interesse desses cruzamentos narrativos, produtores de saberes, fomos em busca de narrativas. Primeiramente, daquelas que narram o que permanece da escola (bem) depois da escola, em seguida, das que se constroem ao longo da experiência na representação das crianças que ainda estão na escola. A narrativa aparece como multifuncional, tanto para expressar quanto para atestar a formação enquanto a constitui.

\section{Contar a escola ao longo do século}

Era uma narrativa que nascia da escuta [...] (TAWADA, 2001, p. 22)

Realizamos uma pesquisa com dez pessoas entre 40 e 80 anos de idade, aproximadamente, para avaliar com base em suas narrativas a pregnância de suas lembranças escolares:

- O que poderiam elas contar anos ou décadas depois?

- Qual o exercício da função narrativa e de quais aprendizagens poderia dar conta a posteriori? 
0 livro ${ }^{6}$ que resultou da pesquisa reúne as narrativas dos participantes sobre o que guardaram de suas experiências escolares. E ele teve consequências inesperadas. Além de ativar as lembranças da escola nos leitores, que começaram espontaneamente a escrever, ele também foi utilizado por professores de francês em suas aulas. Curiosamente, o livro também despertou o interesse de alunos, de hoje, apesar das diferenças fundamentais entre as narrativas apresentadas, qualquer que seja sua época, e a escolaridade no início do século XXI. O cheiro do giz já não é familiar, as carteiras já não são de madeira e um fogão não reina no centro da sala de aula. No entanto, jovens estudantes contemporâneos se reconheceram nos testemunhos de um outro tempo. Como se houvesse invariantes na experiência escolar, como se o que escapava dela guardasse amplamente a mesma essência, para além do tempo, dos programas e das políticas. Embora contingentes, essas narrativas tocavam em algo fundamental, senão universal e transversal, para além dos lugares e dos tempos.

Além da surpresa de ver como a escola com seus aspectos agradáveis e por vezes traumáticos - permanece presente em todos os momentos de suas vidas e está pronta para ressurgir ao menor estímulo, percebemos 0 quanto o que resta dela são, acima de tudo, as emoções, o aspecto relacional e ambiental, mais do que os conteúdos que a escola se empenha em transmitir aos alunos. É o extracurricular que subsiste melhor, o imprevisto, o vínculo humano - com todas as desordens que podem acompanhá-lo -, angústias, vergonhas e outras humilhações. Pelo menos é o que aparece claramente nas aprendizagens. A função do afetivo, do relacional e do sensivel (F2²), fonte da narrativa, é primordial, antes mesmo que o cognitivo possa entrar em ação - e que

6 Lani-Bayle (dir). Raconter l'école au cours du siècle, L'Harmattan, 2000. ela se mantenha dominante ao longo de todo o processo. 0 que é guardado na memória e de longa duração não é (ou não é somente...) o que a escola pede para lembrar.

\section{Contar a escola durante a escolaridade}

Eu quero que alguém me ouça', pensou ela. Eu quero que alguém me ouça, Ishii ou quem quer que seja, não importa. E eu quero sentir, através de cada uma das réplicas de um interlocutor atento, que eu continuo a viver sem ter perdido o tempo que passou até agora. (TSUSHIMA, 2001, p. 185)

Figura 1 - Talkchild

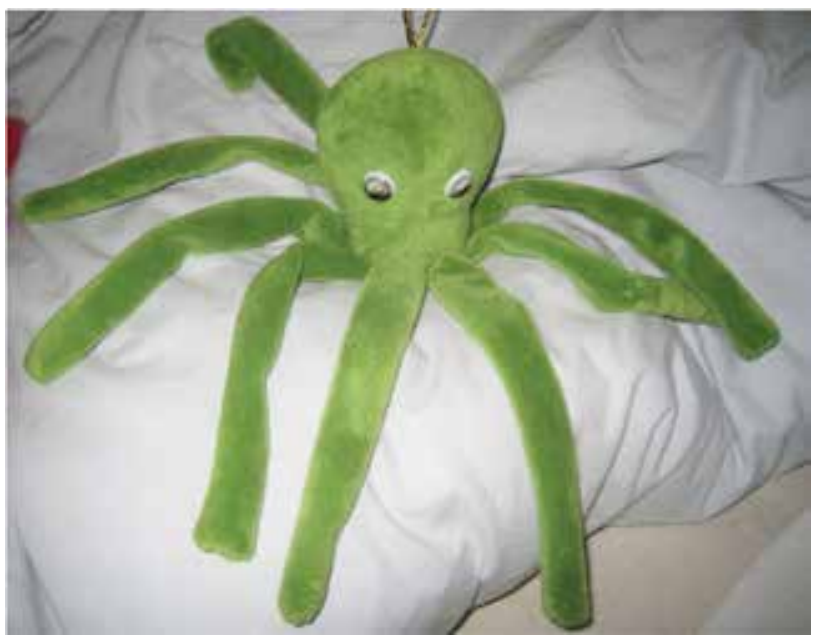

Fonte: fotografia de Martine Lani-Bayle.

Fazendo eco a essas observações, desenvolvemos o projeto de interrogar as representações que têm as crianças da escola e da sua escolaridade, sem esperar que se tornem adultos e se afastem dela ao longo do tempo. A pesquisa se realizou sob a forma de entrevistas, principalmente, com crianças do maternal e do ensino fundamental I. O que dizem as crianças sobre a experiência vivida na escola? Como veem o aspecto relacional no seio da escola (as relações escola/família; relações com os colegas; relações com os professores...)? Sobre sua relação com as atividades escolares (aprendizagens; exigências que lhes são feitas; segurança e ambiente...), sobre sua condição 
de sujeito social e de aprendente? Quais sentidos elas atribuem à escola? Como refletem sobre suas experiências? E por detrás das suas palavras, o que nos ensinam sobre a escola, sobre a qualidade de vida na escola, sobre o tempo da infância vivido na escola?

Para suscitar uma conversa espontânea com as crianças pequenas e evitar uma situação de desequilíbrio ou hierárquica, tão específica da situação escolar, e, a priori, pouco propícia às entrevistas clínico-dialógicas, tivemos a ideia de colocar entre elas e o narrador adulto, um bichinho de pelúcia, que chamamos de Talkchild, que viveria num planeta onde não existe escola. Daí a sua curiosidade sobre o que é a escola. Artificio que tem mediado de forma notável e universal a relação com elas nas entrevistas. Com as crianças maiores, elas dialogavam com um pesquisador estrangeiro (imaginário) que também estava curioso, como Talkchild, e queria saber o que elas viviam na escola. Estávamos pesquisando sobre o que cada criança tinha a dizer sobre isso, o que ela tinha a nos ensinar sobre sua experiência escolar. Além disso, e como já dissemos, estávamos procurando por possiveis invariantes comuns a tal experiência para identificar as divergências, as especificidades tanto as promotoras, quanto as inibidoras. Globalmente:

- Veremos que uma criança de três anos de idade tem dificuldade de se descolar do que sente na escola (nivel F2), a qual ela pode dar muita importância e significação, o que pode impedi-la, às vezes, de pensar e aprender. Por outro lado, suas respostas são imediatamente personalizadas;

- Uma criança de sete anos será mais longamente descritiva e narrativa, mas será dificil encorajá-la a abandonar as respostas que estejam de acordo com as expectativas, mesmo se a pergunta não é indutiva, seu pensamento é, aci- ma de tudo, modelado numa formatação do mundo adulto já bem estabelecida;

- A adolescência se rebelará contra esses condicionamentos, mergulhando no nível F2, primeiro para se fechar como os mais jovens, antes de reinvestir construtivamente neste nivel a favor de uma reflexividade e de uma representação de mundo mais adaptada, tanto ao mundo, quanto a ele próprio no mundo.

Vejamos alguns excertos de suas próprias expressões nas entrevistas.

Primeiras lições da escola, na noite da volta às aulas no maternal:

Yuri, três anos e meio de idade:

Na escola, é só briga. Nos dias sem escola, não tem briga. A tia não tem direito a beijos [...]

Falando direto com Talkchild:

Jason, 3 anos:

"Espere até ser como eu e você vai pra escola".

Colas, 7 anos:

“Você já deve falar francês. [...] Eu vou te explicar matemática...".

Talvez tenha alguns meninos que vão te bater. Vão dizer que você é novinho, por isso vão te bater. [...] Você não tem direito a ter um revolver, então [...] você precisas de alguma coisa que te torne invisivel. [...] É preciso você se esconder [...]

Se você fizer amizade com alguém, aí sim [...] ele pode se defender por você. E para ter um amigo? É preciso que você diga para ele, você quer ser meu amigo? E depois você diz seu nome, diz onde você mora [...]. Eh [...] ele, bom, você vai ter que explicar pra ele, porque ele não sabe aonde é o planeta Marte.

Quem disse que a escola é um lugar tranquilizador e aberto, onde a diferença é, se não esperada, pelo menos é admitida?

Talkchild pergunta: "Aliás, para que a gente vai à escola?". 
Para Colas, a escola é:

[...] para mais tarde. [...] mais tarde. [...] você anda, anda, anda [...]

- E você vai até onde, andando?

Eu não sei nada disso não... isso vai servir pra quando for grande. Quando agente é pequeno, é uma porcaria.

\section{- É duro não é?}

É, dura muito tempo. [...] É preciso esperar. $E^{\prime}$ muito demorado [...]

Esses excertos das primeiras entrevistas mostram rapidamente o que se poderia esperar da fala das crianças sobre a escola, confirmando que a presença do pequeno ser verde, Talkchild, vindo de longe era eficiente e promissora.

Então, depois de tê-los escutado:

- Quem poderia ainda pretender que apenas as operações cognitivas ou apenas as capacidades intelectuais são tratadas na escola?

- Quem poderia ainda pretender que não há necessidade de "proteção" para atravessar o limiar da porta (não se trata aqui de pórticos de segurança ou de homens armados que podem gerar o efeito contrário...) e se sentir suficientemente confiante para aprender?

Além disso, essas narrativas mostram claramente que as crianças são rápidas em apontar os paradoxos da escola (muitas vezes percebida como um lugar agitado e onde há muita gritaria): como vimos, quando vão para lá, elas dão um salto entre um ambiente afetivo-relacional, proximal, conhecido - em princípio tranquilizador - e um segundo (mas não secundário) ambiente distal a ser conhecido, portanto desconhecido - e, a priori, angustiante. Um cruzamento a ser assumido entre emulação e insegurança, entre curiosidade e medo de aprender e/ou de saber, entre autoestima, orgulho, prazer - até mesmo alegrias - e desvalorização, vergonha, humilhação...

Seria possivel encontrar indicações análogas, enfatizando-se a importância das narrativas, em outros países e culturas? Nós pudemos participar de uma experiência de longo prazo realizada no Brasil, que resultou em um livro de narrativas e desenhos de crianças que nós pudemos encontrar nesse país.

\section{Cinco anos de memórias escolares no $\mathrm{NEI}^{7}$ : entre lembranças, descobertas, aprendizagens e diversão ${ }^{8}$}

[...] ele vai pouco a pouco elaborar essa experiência; ele vai the dar uma forma com a ajuda do grafismo, das cores e das palavras, podendo assim representá-la e apresentá-la, colocá-la fora dele mesmo. (AMY, in: CYRULNIK e CONRATH, 2014, p. 55)

Maria Passeggi veio a Nantes para um ano de pós-doutorado comigo (2004-2005) e interessou-se imediatamente por essa pesquisa, que ela estendeu em seu retorno ao Brasil projeto do Conselho Nacional de Desenvolvimento Científico e Tecnológico (CNPq) - com um Talkchild diferente, com asas. ${ }^{9}$ Ela partiu da seguinte pergunta: "Como fazer para garantir que o leitor perceba a palavra da criança com a mesma seriedade com que acolhe a palavra do pesquisador?".

7 Núcleo de Educação da Infância (NEI), Universidade Federal do Rio Grande do Norte (UFRN), Natal-RN, cf Nazário e Galvão, 2018.

8 Esta tradução e as que seguem são provisórias, elas foram realizada por Sueleide de Amorim Suassuna.

9 Então uma criança lhe disse que ele não podia entrar na escola com asas, porque não era permitido voar ali [...] O que tem como contraponto uma observação feita por uma criança francesa ao Talkchild verde: que isso ia sair muito caro em calçados se ele quisesse vir à escola, pois eles não tinham o direito de vir pra escola descalços. O que marca a projeção das crianças para com o pequeno extraterrestre que não tinha escolas em seu planeta. 


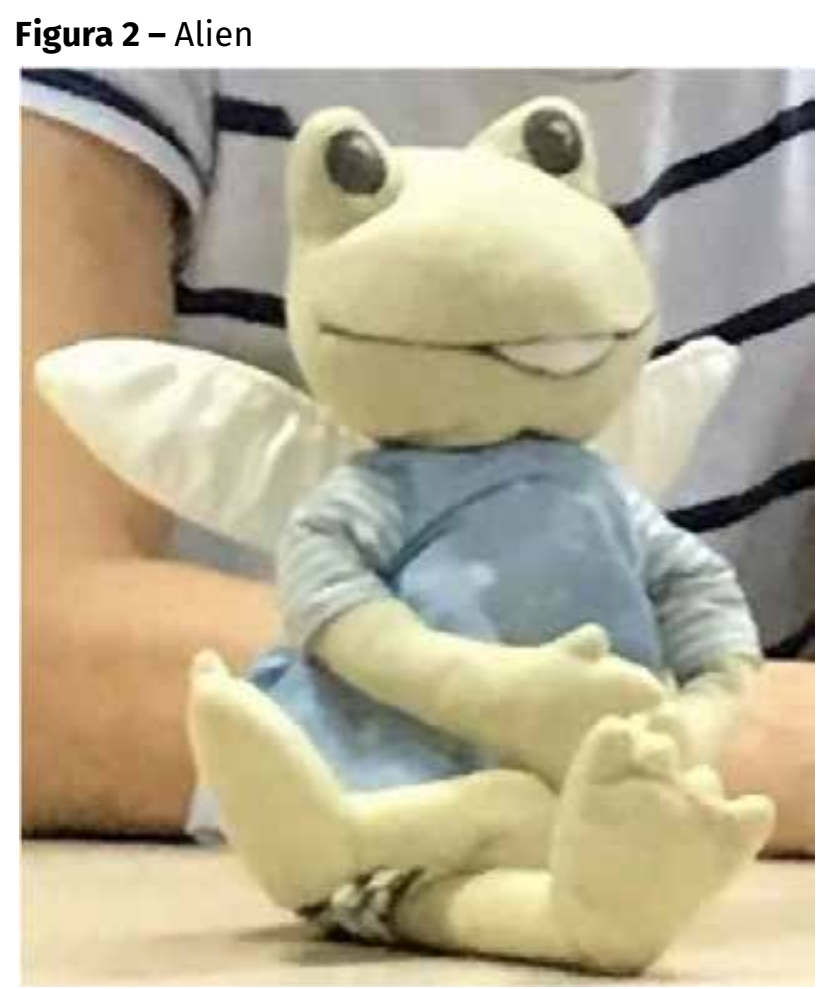

Fonte: fotografia de Martine Lani-Bayle.

E ela foi capaz, depois de ouvir as crianças, de descrever a travessia da educação infantil ao ensino fundamental como uma "trajetória de apagamento", identificando quatro etapas que vão progressivamente de um espaço lúdico a um espaço de aprendizagens:

1. Ingresso na escola: "Na escola, a gente brinca";

2. Início da transição: “A escola serve para tudo";

3. A transição: "A escola serve para estudar e brincar um pouco";

4. Final do 50 ano: "A escola serve para aprender", senão [...] Tobias e Natália dizem: "Se não houvesse escola, seríamos burros!" (PASSEGGI et al., 2014, p. 43-45).

Ela pode assim constatar que "as crianças, em suas narrativas, se situam nessa tensão entre um modo de ser criança e um modo de se constituírem alunos pela injunção inerente à necessidade de estudar, de aprender, de acordo com projetos futuros criados pelo adulto para elas. Essa representação de si opõe-se à liberdade de ser elas mesmas e de fazer o que gostam, "experimentar o bem-estar". Ela então sugeriu que elas escreviam metaforicamente uma história em ambos os lados de uma folha de papel: "Na frente, eles compõem uma autobiografia escolar, com as palavras de outros que eles se forçam a aceitar como tática para se tornarem alunos no processo de enculturação no universo escolar. E no verso, outra autobiografia: a da liberdade e da imaginação, que dá sentido às suas tácticas para permanecerem crianças" (Op. cit. p. 47).

Figura 3 - Cadernos da vida escolar

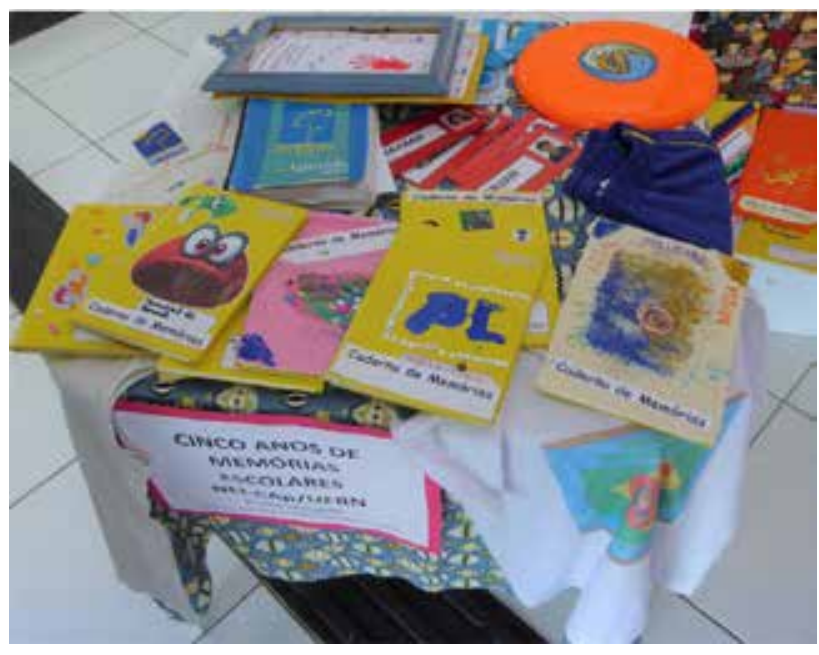

Fonte: fotografia de Martine Lani-Bayle.

Sobre essas bases e para desenvolver essas pistas, uma experiência de cadernos da vida escolar foi implementada em uma escola de Natal. E, em dezembro de 2018, tive o prazer de participar de um simpósio nessa cidade sobre o tema das narrativas infantis.

Na manhã do 2 o dia, tínhamos chegado um pouco cedo e enquanto esperávamos no hall, senti-me atraída por uma exposição de cadernos da vida escolar coloridos. Enquanto olhava curiosa, uma colega que falava bem francês me explicou que eram narrativas de suas memórias escolares, que os alunos de uma escola próxima tinham feito e ilustrado. Na sala, havia um grupo de crianças com cerca de dez anos de idade, que estavam conversando alegremente entre elas. Estávamos num espaço uni- 
versitário e aquilo me surpreendeu, não sabia por que estavam ali. Quando uma das crianças se juntou a nós, perguntando a razão do nosso interesse pelos cadernos. Compreendi, então, que tinham sido feitos por esse grupo de crianças, o que explicava a sua presença. Começamos a conversar em torno dos cadernos com a ajuda da colega que estava traduzindo à medida que íamos avançando. Depois veio uma segunda criança, intrigada pela nossa conversa, mais outra, finalmente todas elas se encontraram reunidas à nossa volta se misturando na conversa. Então, chegou um menino timidamente, depois outro: antes da abertura do anfiteatro para a primeira conferência, todas as crianças estavam à nossa volta para discutir sobre seus cadernos.

E então, surpresa! Vi que eles entraram conosco no auditório e foram diretamente se instalar à mesa, como se fossem qualquer um de nós, alguns deles na fila da frente, porque não conseguiam encontrar um lugar mais atrás! E ninguém parecia incomodado. É verdade, nós não estamos na França! Lembreime de uma única vez em que tentei levar uma criança da idade deles para se sentar comigo à mesa num auditório da Universidade de Nantes (único acordo que consegui ${ }^{10}$, apesar de um grande apelo). Foi em 2010, fui duramente criticada por algumas pessoas na plateia, observando que estávamos numa universidade, por isso não havia lugar para crianças, muito menos na tribuna! E que eu não precisava mostrar um "macaco erudito" num espetáculo, ainda que tivesse encontrado um (ora o tema pelo qual tinham vindo ali era a possibilidade das narrativas de vida para as crianças, por isso não cabia apenas a nós adultos falarmos por elas, as crianças podiam diretamente responder). Então, vários se retiraram furiosos, vendo que eu não deixei a menina sair

10 Este era um acordo tripartite: criança, pais ou responsáveis legais, instituição. e pior, dei-lhe logo a palavra'1! o que ela fez com facilidade e sem se deixar desestabilizar por essas reações, que no mínimo não foram muito agradáveis.

Retornemos a Natal. As crianças estavam lá para apresentar, elas mesmas, o processo que as tinha levado a fazer os cadernos, nos quais contavam suas memórias escolares: elas se apresentaram uma a uma e leram um excerto de sua história. E quando todos falaram, mesmo uma criança com autismo, espontaneamente supervisionada por seus amigos para que ela também pudesse falar, houve uma discussão com a sala sobre a atividade e as experiências. Elas estavam tão confortáveis quanto os adultos em tal situação, quiçá até mais do que alguns! Então, a principal pergunta deles: "Por que nossas histórias interessam a vocês?" E depois: "[...] se vocês estão interessados, a gente se sente importante!". E o que é que lhes fez, o fato de realizar aqueles cadernos? Isso Ihes permitiu recordar os dias de escola e o que faziam, de repente eles tinham escolhido falar sobretudo do que tinham gostado ou sentido prazer de fazer, deixando voluntariamente de fora os momentos menos agradáveis ou mais dificeis. Muito embora, nem sempre os evitaram. Frustrada por não poder ler diretamente os textos deles, prometi-lhes que faria traduzi-los e publicaria o livro na França,12 explicando que para mim o que eles acabavam de fazer, na apresentação, ainda me parecia impossivel de conceber. Eles aceitaram o desafio, assim como suas professoras e os edito-

11 Há ainda progressos serem feitos para se levar em conta as crianças e suas vozes. Quando escrevi este pequeno livro sobre o pensamento de Edgar Morin para crianças (LANI-BAYLE, 2019), várias pessoas me perguntaram em que eu estava me metendo ao tentar pôr ao alcance das crianças um pensamento que se acredita estar reservado apenas aos adultos. De qualquer maneira, as crianças seriam incapazes de compreender...

12 O livro será publicado na França pela L'Harmattan (2020) (No momento da redação dessas linhas, o título do livro não está ainda decidido, devido ao atraso da tradução). 
res do livro que reunia seus textos. Precisamos desse livro, eu agradeço!

Segundo suas professoras, Cláudia e Patrícia Lúcia, que apresentaram essa experiência na introdução ao livro, e o processo que culminou no livro confirmou, foi contemplado por seus testemunhos, e revelou o quanto são importantes para as crianças suas aprendizagens, brincadeiras, explorações e experiências oferecidas pela escola. São iniciativas que thes permitem descobrir as possibilidades dos seus corpos, as potencialidades da vida... As crianças também foram capazes de desenvolver a comunicação entre elas, notadamente, pelo uso da palavra que pode se expressar sob a forma de poesia, permitindo criar "representações" do mundo e sobre o mundo. O que lhes oportunizou também experimentar sua criatividade e até mesmo sua ousadia. Mas essa apresentação vinculou de forma diferente crianças e professores, que as descobriram sob outros aspectos além do desempenho ou comportamento, sensibilizando-as, por exemplo, com relação aos medos que elas sentem, bem como à sua necessidade de exercícios e atividades, de sua curiosidade insaciável - se nada vem sufocá-la.

0 trabalho sobre os textos também permitiu não só dar sentido à observação das regras da escrita e da gramática, mas também um retorno sobre a sua experiência, o que suscitou nas crianças uma tomada de consciência sobre sua forma de aprender, bem como sobre suas necessidades. 0 que mostra claramente que a escola não tem apenas a função de ensinar os conteúdos escolares, mas também a de formação, de educação, quando ela favorece ações que revelam o quanto a escola é marcante para as crianças, ao se integrar profundamente em tudo o que deixará marcas em nas suas jovens vidas.

Breves exemplos do que as crianças têm a dizer:
Caroline (10 anos de idade):

[...] Acho que a leitura é importante porque com ela aprendemos muitas coisas como: respeitar as pessoas e não julgar pelas aparências. Quando lemos, melhoramos nossa leitura, temos mais imaginação para escrever e aprendemos muitas coisas.

\section{Emmanuelle (11 anos):}

Sou eu [...] oi! [...] Ao ler minhas lembranças, você descobrirá coisas sobre minha vida na escola, meus gostos, minhas amizades e muitas outras coisas ainda [...] e isso graças a mim. Divirta-se!

Gyulia (11 anos):

Quando cheguei a esta escola no primeiro ano do fundamental, me senti muito excluída, talvez porque era uma recém-chegada [...] Pouco a pouco comecei a me integrar e aprendi a conhecer melhor esta escola de que gosto tanto hoje. A minha vida aqui tem sido muito boa, mas também muito complicada! Imaginem só! Acordar todos os dias às 6:00 da manhã! É muito difícil e como se não bastasse, você tem que estudar também (algumas pessoas dizem que é normal para crianças, mas eu não acho). As coisas normais para crianças é brincar, correr, pular, se divertir e depois pedir mais!

Nas suas narrativas, vemos que todas as crianças se dirigem aos leitores. A temporalidade é bem localizada, e retornam muitas vezes ao início dos episódios escolares atuais, podendo se projetar no futuro. A narrativa é bastante reflexiva, associando a ela a distância, o bom humor e até mesmo poesia. Ela não é composta apenas de frases e textos, mas também de projetos que contribuem muito para a construção da identidade narrativa de que temos falado (as crianças esboçaram seu retrato para se apresentar); a narratividade visual que integra o fator tempo se apresenta na folha em duas dimensões, enquanto as frases se sucedem nas linhas. A tecelagem do texto e das imagens aumenta o alcance narrativo bem como o alcance reflexivo do conjunto. 
Percebemos, nas pesquisas conduzidas no Brasil, a importância de levar em conta a cultura de acordo com as regiões, bem como a natureza, o que é muito mais evidente do que na França, por exemplo. A escola para ser aceita pelos povos indígenas precisa não estar em desacordo com eles: deve respeitar as crianças ao ensiná-las. Deve também permitir que as crianças se expressem e trabalhem em diálogo - a prática dos "círculos reflexivos" -, não só com os adultos, mas também entre elas. Em uma escola na amazônia, por exemplo, não é raro ouvir crianças pedindo ao professor para ficar calado e deixá-las trabalhar (o contrário do que é observado na França!). Isso faz lembrar a frase que está no título de um livro de Jérôme Bruner: ... car la culture donne forme à l'esprit (1991). Assim, no decorrer da pesquisa aqui descrita, e como observa Furlanetto e demais autores (2014), constata-se que, no Brasil, as crianças

[...] são capazes de nos mostrar o mundo de maneira diferente [...]. Elas ainda não estão totalmente contaminadas pelas 'verdades' às quais já estamos acostumados e que não questionamos mais. Elas abrem nossos olhos e nos permitem ver o novo como algo verdadeiramente novo. Elas são capazes de nos surpreender assim como elas próprias se surpreendem. (FURLANETTO, et. al., 2014, p. 67)

Os saberes a adquirir, se não são relevantes para a escola, eles são sempre deixados bem para trás. Os filtros que os autorizam ou bloqueiam são, portanto, fundamentais. E as crianças, que são, em geral, perfeitamente capazes de se expressar sobre si mesmas e contar-nos sua experiência, podem nos indicar a pregnância, a valência e o alcance, para elas, sobre como se sentem em relação ao significado, à legitimidade e à intenção. E quando seu tempo de escola toma corpo sob a forma de narrativas, elas se tornam criativas ou mesmo empreendedoras, confiantes e até conquista- doras em sua exploração rumo à descoberta do mundo.

\section{Referências}

AFEV, Association de la vie étudiante pour la ville, Baromètre Trajectoires 2009. Disponible à: www.trajectoires-reflex.org Accessible em: 15 abr. 2020.

AMY, Marie-Dominique. Comment aider l'enfant autiste. Approche psychothérapique et éducative. $\mathrm{Pa}$ ris: Dunod, 2013.

BENAMEUR, Jeanne. Les demeurées. Paris: Babelio, 2000.

BOIMARE, Serge. L'Enfant et la peur d'apprendre. Paris: Dunod, 1999.

BRAUD, Manuela; HUBERT, Bruno. Pour une approche dialogique de la question du bien-être. Recherche et Education, Paris: Société Binet-Simon n ${ }^{\circ}$ 17, p. 1-10, 2017. Disponible à: https://journals.openedition.org/rechercheseducations/3775?lang=en Accessible em 15 mar. 2020.

BROUGÈRES, Gilles; VANDENBROECK, Michel (dir). Repenser l'éducation des jeunes enfants, Berne (Suisse): PIE Peter Lang, 2007 [2008].

BRUNER, Jérôme. Car la culture donne forme à l'esprit: de la révolution cognitive à la psychologie culturelle. Paris: Eshel, 1991.

BRUNER, Jérôme. Pourquoi nous racontons-nous des histoires? Paris: Retz, 2002.

Chemins de formation $n^{\circ}$ 10-11. La démarche clinique en éducation et recherche. Paris: L'Harmattan, 2007. Disponible à: https://www.editions-harmattan.fr/index.asp?navig=catalogue\&obj=numero\&no=49554\&no_revue $=876$ Accessible em: 15 abr. 2020.

CHAR, René. Fureur et mystères. Paris: Gallimard Poésie, 1948.

CHATELLIER, Cecile. Les paradoxes de l'échec scolaire en cycle 3: construction, détours, autonomie. 2000. Tese (Doutorado em Ciências da Educação). Universidade de Nantes, 2000. 
Chemins de formation $n^{\circ} 17$. Récits pour enfants, récits d'enfants, récits d'enfance. Paris: L'Harmattan, 2013.

CIFALI, Mireille; GIUST-DESPRAIRIES, Florence (dir). De la clinique. Un engagement pour la formation et la recherche. Louvain-la-Neuve (Belgique): De Boeck, 2006.

CIFALI, Mireille; GIUST-DESPRAIRIES, Florence (dir). Formation clinique et travail de pensée. Louvain -la-Neuve (Belgique): De Boeck, 2008.

CUNY, Marie-Thérèse; ANGEL, Sylvie (coll.). Ce que je ne peux pas vous dire. Que se passe-t-il dans les collèges? 26 collégiens parlent sans retenue. Paris: Pocket 11975 Oh! Editions, 2003.

CYRULNIK, Boris. Ivres paradis, bonheurs héroïques. Paris: Odile Jacob, 2016.

CYRULNIK, Boris; CONRATH, Patrick. Raconter des histoires. Un étrange besoin. Revigny-sur-Ornain: Les éditions du Journal des psychologues, 2014.

Enfants et Enseignants vous racontent leur vie à l'école. Disponible à: http://lorival.eklablog.com/ Accessible em: 15 abr. 2020.

DELERM, Philippe. Ma grand-mère avait les mêmes: les dessous affriolants des petites phrases. Paris: Seuil, 2008.

DOLTO, Françoise. Tout est langage. Paris: Vertiges du Nord/Carrere, 1987.

FURLANETTO, Ecleide; GOMES, Marineide; PASSEGGI, Maria da Conceição. Pour être à l'école, il faut se couper les ailes: les enfants racontent la place du corps à l'école. In: LANI-BAYLE, Martine et PASSEGGI, Maria. Raconter l' école: à l'écoute de vécus scolaires en Europe et au Brésil. Paris: L'Harmattan, 2014. p. 59-68.

HANDKE, Peter. Gaspard. Paris: L'Arche, 1971 (1967).

GOLSE, Bernard; MISSONNIER, Sylvain (dir.). Récit, attachement et psychanalyse. Pour une clinique de la narrativité. Toulouse: Érès, 2005 [2008].

HUSTON, Nancy. L'Espèce fabulatrice. Paris: Babel n 1009, Actes sud, 2008.
LAGARDE, Claude et alii. Pour une pédagogie de la parole. De la culture à l'éthique. Paris: ESF, 1995.

LANI, Martine. Enfants déchirés: enfants déchirants. Paris: Éditions universitaires, 1983.

LANI-BAYLE, Martine. L'Enfant et son histoire. Vers une clinique narrative. Toulouse: Érès, 1999.

LANI-BAYLE, Martine (coord.). Raconter l'école au cours du siècle. Paris: L'Harmattan, 2000.

LANI-BAYLE, Martine. Vers une pédagogie de la parole et de l'écoute? La place de la parole dans la genèse des savoirs. Paris: Cahiers pédagogiques, septembre 2001. Accessible em 15 abr. 2020.

LANI-BAYLE, Martine. Taire et transmettre. Les histoires de vie au risque de l'impensable. Lyon: Chronique Sociale, 2006.

LANI-BAYLE, Martine. A criança e sua história. Por uma clínica narrativa. Natal (Brésil): EdUfrn, 2018.

LANI-BAYLE, Martine dir. Mettre l'expérience en mots. Les savoirs narratifs. Lyon: Chronique sociale, 2019.

LANI-BAYLE, Martine. Clinique-dialogique et histoires de vie; Enfance et récits. In: DELORY-MOMBERGER, Christine (dir). Vocabulaire des histoires de vie et de la recherche biographique. Toulouse: Erès, 2019. p. 310-312.

LANI-BAYLE, Martine; Passeggi Maria dir. Raconter l'école. À l'écoute de vécus scolaires en Europe et au Brésil. Paris: L'Harmattan, 2014.

LANI-BAYLE, Martine; RONXIN, Adélaïde. Dis, raconte, comment ça marche? Découvrir et penser le monde avec Edgar Morin. Cholet: Pourpenser éditions, 2019.

LANI-BAYLE, Martine; SLOWIK, Aneta (dir). Récits et résilience, quels liens? Chemins de vie. Paris: L'Harmattan, 2016.

LANI-BAYLE, Martine; TEXIER, François. Apprivoiser l'avenir pour et avec les jeunes. Entretiens intergénérationnels avec André de Peretti. Paris: Mare et Martin, 2007.

LARROSA, Jorge. Apprendre et être. Paris: ESF, 1998. 
Léo et Léa racontent l'école. Disponible à: http:// www.leblogbebe.com/2009/10 Accessible em: 15 abr. 2020.

MEIRIEU, Philippe. Écriture et recherche. Paris: Cahiers pédagogiques. CRAP. Écrire. Un enjeu pour les enseignants. Université d'été, 1993. p. 111-129.

MONTANDON, Cléopâtre. L'Éducation du point de vue des enfants. Paris: l'Harmattan, 1997.

MORIN, Edgar. Les Sept savoirs nécessaires à l'éducation du futur. Paris: Seuil, 2000.

MORIN, Edgar; MOTTA, Raul; CIURANA, Émilio-Roger. Éduquer pour l'ère planétaire. La pensée complexe comme Méthode d'apprentissage dans l'erreur et l'incertitude humaines. Paris: Balland, 2003.

NATANSON, Madeleine. Des adolescents se disent. Paris: De Boeck \& Belin, 1998.

NAZÁRIO, Cláudia; GALVÃO, Patrícia Lúcia. Cinco anos de memórias escolares no NEI: entre lembranças, descobertas, aprendizagens e diversão. Natal: UFRN-NEI, 2018.

PASSEGGI, Maria da Conceição et al. L'enfance à l'école: scénarios et enjeux de la Recherche avec des enfants au Brésil. In: LANI-BAYLE, Martine et PASSEGGI, Maria da Conceição. Raconter l' école: à l'écoute de vécus scolaires en Europe et au Brésil. Paris: L'Harmattan, 2014. p. 33-47.

PERRAUDEAU. Michel, Échanger pour apprendre. Paris: Armand Colin, 1998.

PIAGET, Jean. La Représentation du monde chez l'enfant. Paris: PUF, 1947 [1999].

RICEUR, Paul. Temps et récits ( 3 tomes). Paris: Essais Points Seuil, 1983.

RICEUR, Paul. Soi-même comme un autre. Paris: Seuil 1990.

TAWADA, Yoko. Narrateurs sans âmes. Paris: Verdier, 2001.

TAYLOR, Alex. Bouche bée, tout ouïe... ou comment tomber amoureux des langues. Paris: Jean-Claude Lattès, 2010.

TSUSHIMA, Yûko. Vous, rêves nombreux, toi, la lumière! Arles: Picquier poche $n^{\circ}$ 154, 2001 [1991].

VASCONCELOS, Sandra. Penser l'école et la construction des savoirs. Étude menée après d'adolescents cancéreux au Brésil. 2003, 268f, Tese (Doutorado em Ciências da Educação), Universidade de Nantes, 2003.

VICTORRI, Bernard. Homo narrans: le rôle de la narration dans l'émergence du langage. Langages $n^{\circ}$ 146. Paris: Armand colin, 2002. Accessible em 15 abr. 2020.

WINNICOTT, Donald Woods. Le destin de l'objet transitionnel. Journal de la psychanalyse de l'enfant, $\mathrm{V}$. 6, n. 1, p. 17-24. Paris: PUF 2016 [1959].

Tradução: Maria da Conceição Passeggi, professora da Universidade Federal do Rio Grande do Norte (UFRN) e da Universidade Cidade de São Paulo (Unicid); e Sandra Maia-Vasconcelos, professora da Universidade Federal do Ceará (UFC). Fotografias: Martine Lani-Bayle.

Martine Lani-Bayle é professora emérita em Ciências da Educação da Universidade de Nantes, pesquisadora do Centre de Recherche en Éducation de Nantes (CREN) - www.lanibayle.com. E-mail: martine.lani-bayle@dartybox.com 